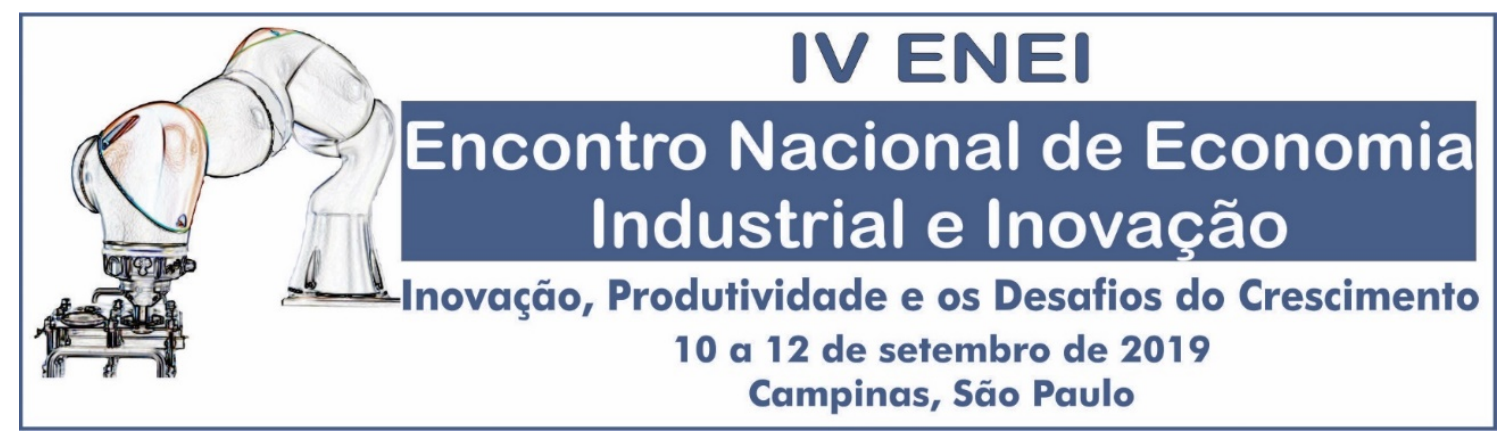

\title{
Influência metodológica na desindustrialização brasileira e correções na composição setorial do PIB
}

\author{
Paulo César Morceiro (FEA-USP) ${ }^{1}$
}

Área ABEIN: 1.4 - Padrões de especialização produtiva e desenvolvimento.

Resumo. Usuários das Contas Nacionais do Brasil, da segunda metade do século XX, frequentemente calculam incorretamente a participação setorial no PIB. Esse cálculo inadequado sobrestima a participação setorial devido ao dummy financeiro não ser eliminado do PIB setorial. Isso afeta o nível, pico e formato da série de participação setorial de longo prazo, logo, têm implicações para o debate de desindustrialização. As mudanças metodológicas também causaram quebras seriais entre 1989 e 1990 e entre 1990 e 1995 . Foi criado um método para eliminar o problema do dummy financeiro e das mudanças metodológicas, dessa maneira, este estudo exibe séries corrigidas da participação setorial no PIB de 1947 a 2017 compatibilizadas para a metodologia atual do IBGE. A série corrigida está mais aderente aos ciclos econômicos e permite um melhor entendimento da desindustrialização do Brasil. Este estudo também apresenta séries oficiais novas e mais extensas da participação da indústria de transformação no PIB na mesma metodologia que permitem um melhor entendimento da desindustrialização brasileira no período anterior e posterior a abertura comercial, período de difícil interpretação devido às mudanças metodológicas.

Palavras-chave: Mudança estrutural; desindustrialização; contas nacionais; mudanças metodológicas; dummy financeiro.

\begin{abstract}
Users of Brazilian National Accounts, of the second half of the twentieth century, often incorrectly calculate sectoral participation in GDP. This inadequate calculation overestimates the sectoral share because the financial dummy doesn't be eliminated from the sectoral GDP. This affects the level, peak and format of the long-term sectoral participation series, thus, it has implications for the de-industrialization debate. Methodological changes also caused serial discontinuities between 1989 and 1990 and between 1990 and 1995 . A method was created to eliminate the problem of the financial dummy and methodological changes, in this way, this study shows corrected series of GDP sectoral composition from 1947 to 2017 compatible with the IBGE's current methodology. Corrected series are more consistent with economic cycles and allow a better understanding of the Brazilian deindustrialization. This study also presents new and more extensive official series of the manufacturing sector's share in GDP in the same methodology that allow a better understanding of the Brazilian deindustrialization in the period before and after the trade opening, period of difficult interpretation due to the methodological changes.
\end{abstract}

Keywords: Structural change; deindustrialization; national accounts; methodological changes; financial dummy.

Classificação JEL: E23; L16; O14.

\section{Introdução}

${ }^{1}$ Doutor em Economia pela FEA-USP. E-mail: paulo.morceiro@gmail.com. O autor agradece a Celso Neris Junior e a Milene Simone Tessarin por lerem e comentarem este texto, isentando-os de erros e imprecisões remanescentes. 
As sociedades passaram por grandes transformações desde a Revolução Industrial. A renda per capita multiplicou-se várias vezes, a cesta de consumo diversificou bastante e a organização do trabalho mudou radicalmente. Os países que progrediram na industrialização melhoraram seus índices de desenvolvimento humano e apresentaram avanços científicos e tecnológicos substantivos. No Brasil, houve progresso na industrialização até a primeira metade dos anos 1980, ainda reflexo da maturação dos investimentos do segundo Plano Nacional de Desenvolvimento (II PND) implementado na segunda metade da década anterior. O grau de industrialização do Brasil - mensurado pela participação percentual da indústria de transformação no Produto Interno Bruto (PIB) ${ }^{2}$ - aumentou significativamente até o pico de 36\%, em 1985 (BONELLI; PESSÔA, 2010, p. 14). No entanto, a partir da década de 1980, a indústria de transformação cresceu abaixo da modesta taxa de crescimento da economia brasileira na maioria dos anos e, consequentemente, o grau de industrialização reduziuse significativamente para 11,3\% em 2018, conforme dados do IBGE (2018a) - ressalta-se que este percentual é o menor nível da série oficial iniciada em 1947.

A redução do grau de industrialização - somado a outros fatores, por exemplo, aumento do coeficiente importado em vários setores industriais e fraca performance dos indicadores sociais, científicos e tecnológicos - provocou um intenso debate se o Brasil passou por um processo de desindustrialização e quais seriam suas consequências para o desenvolvimento futuro. Hiratuka e Sarti (2017) realizaram uma síntese atualizada desse debate.

No Brasil, o formato da série de participação da manufatura no PIB tem contribuído para fomentar esse debate, uma vez que essa série é exibida frequentemente nos jornais (Estadão, Folha de São Paulo, Valor Econômico) de grande circulação do país. No entanto, não é possível comparar o grau de industrialização de 1985 com o do século XXI devido às mudanças metodológicas implementadas pelo Instituto Brasileiro de Geografia e Estatística (IBGE) que geraram duas descontinuidades na série de participação da manufatura no PIB - uma entre 1989 e 1990 e outra entre 1994 e 1995 (tal assunto será melhor tratado na seção 3.1). Devido à ausência de dados comparáveis na mesma metodologia é difícil avaliar se indústria perdeu importância no período anterior e durante a abertura comercial brasileira (TORRES; CAVALIERI, 2015, p. 865-867). Vale ressaltar que uma parte da literatura responsabiliza a abertura comercial como uma das causas da desindustrialização.

Bonelli e Pessôa (2010) realizaram um ajuste na série de participação da manufatura no PIB de 1947 a 2008 para eliminar as duas descontinuidades metodológicas e concluíram que o Brasil estava sobreindustrializado até meados da década de 1980, pois a manufatura brasileira possuía participação no PIB muito superior à prevista por um modelo econométrico com dados de 156 países. Para esses autores, as políticas de industrialização por substituição de importações enviesaram a estrutura produtiva a favor da indústria e a redução do grau de industrialização desde a segunda metade da década de 1980 trouxe o Brasil para o padrão normal do seu estágio de desenvolvimento. Assim, para Bonelli e Pessôa (2010), a diminuição do grau de industrialização brasileiro foi um ajustamento normal.

Este estudo tem dois objetivos que visam contribuir com a discussão brasileira sobre mudança estrutural - principalmente, sobre desindustrialização - mensurada pela participação dos setores no PIB ao apresentar novas evidências empíricas.

O primeiro objetivo procura informar os usuários das Contas Nacionais brasileiras que eles geralmente mensuram a participação setorial no PIB de modo errado, pois a soma de todos os setores

\footnotetext{
${ }^{2}$ Neste estudo utilizamos sem distinção os termos indústria de transformação e manufatura. Em todo o trabalho o PIB está mensurado a preços básicos ou a custo de fatores, nunca a preços de mercado. O PIB a preços básicos ou a custo de fatores corresponde a soma do valor adicionado bruto de todos os setores de atividade da economia.
} 
de atividade ultrapassa $100 \%$ do PIB nas Contas Nacionais anteriores ao Sistema de Contas Nacionais Referência 2000 (SCN Ref. 2000) (ver seção 3.2). Como consequência, a série de participação da manufatura no PIB está sobrestimada nas metodologias antigas das Contas Nacionais.

O segundo objetivo visa desenvolver um método para ajustar a série de participação da manufatura no PIB levando em conta as descontinuidades metodológicas e o erro mencionado. Ao fazer isso gerase uma série nova de participação da manufatura no PIB ajustada e compatibilizada para a metodologia atual das Contas Nacionais do IBGE (ver seção 4.2).

Este trabalho traz informações novas para o debate nacional sobre desindustrialização. Primeiro, a seção 3.1 exibe séries de participação da indústria de transformação no PIB construídas na mesma metodologia para períodos mais extensos que os disponíveis atualmente para o Brasil. Dessa maneira, essas séries - além de cobrir o período das quebras metodológicas - permitem analisar se houve desindustrialização no período anterior e posterior a abertura comercial e supre a carência de dados, comparáveis na mesma metodologia, apontada por Torres e Cavalieri (2015). Segundo, apresenta-se evidências na seção 3.2 de que a série de participação da indústria de transformação no PIB brasileiro está sobrestimada no período anterior e durante a liberalização comercial devido à forma incorreta como a série foi mensurada em vários estudos ${ }^{3}$, dessa forma, tais evidências colocam em dúvida a tese da sobre-industrialização de Bonelli e Pessôa (2010) e Bonelli, Pessôa e Matos (2013). Ademais, na seção 4, desenvolve-se um método mais eficiente que o método tradicional para corrigir as descontinuidades metodológicas na série de (des)industrialização e, também, para eliminar a sobrestimação mencionada. A seção 5 conclui o estudo e a seguir há o referencial teórico.

\section{Referencial teórico}

A desindustrialização é entendida como um declínio absoluto ou queda sustentada da participação da indústria de transformação no PIB e no emprego (SINGH, 1987, p. 302; TREGENNA, 2009, p. 459). Recentemente, o influente artigo de Rodrik (2016) mensurou a desindustrialização como uma redução da manufatura no PIB - a preços correntes e a preços constantes - ou no emprego total para um grupo formado por 42 países desenvolvidos e em desenvolvimento. Em geral, nos países desenvolvidos, predominam diagnósticos de desindustrialização pela ótica do emprego e, nos países em desenvolvimento, pela ótica do PIB (TREGENNA, 2016a). No Brasil, os estudos concentram-se no PIB (MORCEIRO, 2012, p. 43).

A concentração no PIB ou emprego deve-se a fatores econômicos, políticos e disponibilidade de dados. Nos países desenvolvidos houve uma redução da parcela manufatureira mais rápida no emprego total que no PIB - ver Tregenna (2016a, p. 99, 2016b, 712-715), por exemplo -, dessa maneira, o tema da desindustrialização pelo emprego adentrou nos assuntos políticos, principalmente, devido aos efeitos do comércio internacional sobre o emprego industrial. Nos países em desenvolvimento há maior disponibilidade de dados setoriais para o valor adicionado e a ausência de séries setoriais longas de emprego tem sido um limitante para analisar a desindustrialização pelo emprego (TREGENNA, 2016a). No caso brasileiro, além da indisponibilidade de dados anuais de empregos por setor de atividade, a redução da parcela manufatureira no PIB foi muito elevada a partir de meados da década de 1980 até os dias de hoje, justificando o foco dos diagnósticos da desindustrialização pelo PIB.

Ressalta-se que existem muitas abordagens sobre desindustrialização. Morceiro (2012, p. 43-57) fez um amplo levantamento na bibliografia nacional e estrangeira e verificou que além da análise pelo

\footnotetext{
${ }^{3}$ Por exemplo, Bonelli e Pessôa (2010, p. 14), Morceiro (2012, p. 102), Bonelli, Pessôa e Matos (2013, p. 49) Torres e Cavalieri (2015, p. 866), compilador IPEADATA, entre outros. Provavelmente, o IPEADATA contribuiu para difundir a série dado que é um compilador muito utilizado no Brasil como fonte de informação.
} 
PIB e pelo emprego, no Brasil, há um outra abordagem que mensura a desindustrialização pela diminuição do coeficiente de agregação de valor - isto é, redução do valor da transformação industrial no valor da produção industrial. Além disso, Morceiro (2012) verificou que uma parcela da literatura internacional - denominada "visão de Cambridge" - capta a desindustrialização pelo comércio exterior através da deterioração do saldo comercial da indústria de transformação, especialmente quando gera problemas para o balanço de pagamentos e à autonomia da política macroeconômica.

Neste estudo vamos trabalhar apenas com a definição de desindustrialização mensurada pelo PIB a preços correntes e para a economia brasileira. Assim, desindustrialização (industrialização) é a redução (aumento) do grau de industrialização mensurado pela participação da indústria de transformação no PIB do Brasil. O grau de industrialização é um indicador simples que sintetiza a evolução da (des)industrialização de um país. À medida que um país se industrializa (desindustrializa) o grau de industrialização aumenta (diminui), pois a indústria de transformação cresce a uma taxa superior (inferior) ao do restante da economia e aumenta a sua contribuição na geração de riqueza anual.

Até meados da década de 1980 houve progresso na industrialização brasileira ao implantar setores ausentes na matriz produtiva e enraizar localmente a produção de insumos e componentes. A manufatura liderou o crescimento econômico e a elevação da renda per capita, principalmente desde a década de 1950. Com isso, o grau de industrialização aumentou de $19 \%$ para $36 \%$ entre 1950 e 1985 conforme dados do SCN Consolidadas apresentados por Bonelli e Pessôa (2010, p. 14). Nesse período, foram implantados os setores da indústria pesada e de elevada intensidade em capital (como bens intermediários e bens de consumo duráveis) e as indústrias de bens de capital.

No entanto, a partir da década de 1980 a manufatura brasileira cresceu pouco e passou a contribuir cada vez menos para a formação do PIB. Além disso, o aumento do conteúdo importado ${ }^{4}$ em vários setores industriais aumentou e os indicadores sociais, científicos e tecnológicos tiveram pouca evolução nas últimas décadas no comparativo internacional. Diante desse quadro, vários autores realizaram diagnósticos sobre a existência de desindustrialização no Brasil, como Palma (2005), Feijó, Carvalho e Almeida (2005), Nassif (2008), Bresser-Pereira e Marconi (2010), Bonelli e Pessôa (2010), Oreiro e Feijó (2010), Marconi e Rocha (2012), Cano (2012), Nassif, Bresser-Pereira e Feijó (2017) e Morceiro (2012, 2018). Hiratuka e Sarti (2017) fizeram uma síntese atualizada desse debate e apontaram que ele possui implicações diferentes dependendo da corrente teórica de cada autor.

Para Bonelli e Pessôa (2010) não é possível comparar diretamente o grau de industrialização da década de 1980 com o do século XXI porque a metodologia de cálculo do PIB pelo IBGE mudou. Esses autores apresentaram uma nova série com metodologia comparável ao longo do período (de 1947 a 2008), eliminando dessa forma as descontinuidades. Na nova série, foi constatada uma queda de 13 p.p. no grau de industrialização, pois a manufatura reduziu seu peso de $36 \%$ para $23 \%$ do PIB entre 1985 e 2008 (BONELLI; PESSÔA, 2010, p. 16). Esses autores desenvolveram a tese de que o Brasil estava sobre-industrializado no período anterior à liberalização comercial a partir dos resultados de um modelo econométrico com dados para cerca de 150 países. Eles verificaram que a manufatura brasileira registrou uma participação no PIB muito superior à prevista pelo modelo, que foi estimado em função do estágio de desenvolvimento econômico do país captado pelo produto per capita, dotação de fatores naturais, tecnologia (relação capital-trabalho) e densidade populacional. Bonelli, Pessôa e Matos (2013) utilizando uma especificação econométrica diferente do estudo anterior chegaram a resultados semelhantes: até meados da década de 1980, o Brasil passou por uma doença soviética, isto é, a indústria de transformação teve uma participação no PIB muito acima do padrão internacional quando se controla algumas variáveis pelo estágio de desenvolvimento.

\footnotetext{
${ }^{4}$ Ver, por exemplo, Moreira (1999), Feijó (2007) e Morceiro (2012, cap. 3).
} 
Vale ressaltar que pouquíssimos países altamente industrializados alcançaram grau de industrialização da ordem de $36 \%$ do PIB e, os poucos casos - Inglaterra, Alemanha e Japão detinham fatia relevante das exportações mundiais, o que nunca ocorreu para o Brasil. Nos Estados Unidos, considerado a maior potência industrial do século $\mathrm{XX}$, a manufatura nunca superou o nível de $30 \%$ do PIB. Nessa perspectiva, a tese da sobre-industrialização de Bonelli e Pessôa (2010) parece fazer sentido.

Torres e Cavalieri (2015) reconheceram que o grau de industrialização é um dos principais indicadores utilizados pela literatura brasileira de desindustrialização, mas possui viés devido às descontinuidades metodológicas. Para eles, essas descontinuidades tornam o indicador inadequado para análises sobre desindustrialização no período anterior a 1995.

Diante disso, torna-se difícil avaliar se a indústria perdeu importância na economia brasileira a partir dos dados disponíveis e, principalmente, apontar a abertura econômica como marco determinante da desindustrialização. Para fazer esse tipo de análise, seria necessário que os dados anteriores à década de 1990 fossem comparáveis com dados posteriores à abertura comercial. (TORRES; CAVALIERI, 2015, p. 867).

A próxima seção exibe as descontinuidades metodológicas para a indústria de transformação e mostra evidências empíricas que colocam em dúvida tese da sobre-industrialização de Bonelli e Pessôa (2010).

\section{A influência metodológica das Contas Nacionais do Brasil no PIB setorial}

Esta seção está organizada em duas subseções. A seção 3.1 exibe as fontes de informação e a série considerada oficial da participação da manufatura no PIB brasileiro. A seção 3.2 apresenta dados e argumentos que indicam que a série considerada oficial está sobrestimada devido ao dummy financeiro.

\subsection{Fontes de informação e série oficial da participação da manufatura no PIB}

As fontes de informação deste estudo são as várias versões das contas nacionais do Brasil resumidas no Quadro $1 .{ }^{5}$ A sexta coluna deste quadro exibe o marco teórico que cada sistema de contas nacional (SCN) adota, ou seja, mostra quais manuais referenciaram os conceitos e instruções para a mensuração do sistema. Atualmente, o System of National Accounts 2008 (SNA 2008, 2009) é o marco teórico em vigor adotado pelos países e o Brasil.

Com o intuito de revisar conceitos e metodologias, mudar o ano-base ou o ano de referência, implementar classificação setorial e de produtos mais detalhada e adotar fontes de informação mais consistentes para alimentar o SCN, periodicamente, uma nova versão do marco teórico é desenvolvida. A implementação desta versão nova pelo IBGE leva alguns anos e, enquanto isso, os resultados são divulgados com base na versão anterior. No entanto, à medida que uma nova versão das contas nacionais é divulgada, o período considerado oficial altera-se, pois ela retroage alguns anos. Dessa maneira, para alguns anos há informações do PIB setorial do Brasil a partir de dois ou três SCN diferentes.

\footnotetext{
${ }^{5}$ De 1949 a 1986, a Fundação Getúlio Vargas (FGV) era a instituição responsável pelas Contas Nacionais do Brasil, com resultados publicados para 1947 até início da década de 1980. A partir de dezembro de 1986, o IBGE passou a elaborálas. Como as estatísticas divulgadas pela FGV não eram homogêneas entre os diversos períodos publicados, o IBGE revisou e padronizou os resultados divulgados anteriormente de forma a tornar as séries comparáveis. A série revisada intitula-se "Sistema de Contas Nacionais Consolidadas" ou "Contas Consolidadas para a Nação" e se baseia na metodologia IBGE (1990a).
} 
Quadro 1 - As contas nacionais oficiais do Brasil, de 1947 a 2018

\begin{tabular}{|c|c|c|c|c|c|c|c|}
\hline $\begin{array}{l}\text { Período } \\
\text { de } \\
\text { vigência }\end{array}$ & $\begin{array}{l}\text { Instituição } \\
\text { responsável }\end{array}$ & Nome da série & $\begin{array}{c}\text { Referência } \\
\text { bibliográfica }\end{array}$ & $\begin{array}{l}\text { Ano base ou } \\
\text { de referência }\end{array}$ & $\begin{array}{l}\text { Marco } \\
\text { teórico }\end{array}$ & $\begin{array}{l}\text { Período coberto e } \\
\text { agregação setorial } \\
\text { (S) }\end{array}$ & $\begin{array}{l}\text { Período oficial da } \\
\text { série de } \\
\text { desindustrialização }\end{array}$ \\
\hline $\begin{array}{c}1949 \mathrm{a} \\
1986\end{array}$ & FGV-IBGE & $\begin{array}{c}\text { Sistema de Contas } \\
\text { Nacionais } \\
\text { Consolidadas (SCNC) }\end{array}$ & $\begin{array}{c}\text { IBGE } \\
(1990 \mathrm{a}, \\
2006)\end{array}$ & $\begin{array}{l}1947 ; 1956 \\
1960 ; 1970\end{array}$ & $\begin{array}{l}\text { SNA- } \\
53\end{array}$ & $\begin{array}{c}1947 \text { a } 1979 \\
(11 \mathrm{~S} \text { de } 1947-1969 \text { e } \\
36 \mathrm{~S} \text { de } 1971-1979)\end{array}$ & 1947 a 1979 \\
\hline $\begin{array}{c}1987 \mathrm{a} \\
1996\end{array}$ & IBGE & $\begin{array}{l}\text { Contas Consolidadas } \\
\text { para a Nação (CCN) }\end{array}$ & $\begin{array}{c}\text { IBGE } \\
(1990 \mathrm{a}, \\
1994,1996)\end{array}$ & 1980 & $\begin{array}{l}\text { SNA- } \\
68\end{array}$ & 1980 a $1995(36 \mathrm{~S})$ & 1980 a 1989 \\
\hline $\begin{array}{l}1997 \mathrm{a} \\
2006\end{array}$ & IBGE & $\begin{array}{c}\text { Sistema de Contas } \\
\text { Nacionais } \\
\text { (SCN Ref. 1985) }\end{array}$ & $\begin{array}{l}\text { (IBGE, } \\
\text { 2004a) }\end{array}$ & 1985 & $\begin{array}{l}\text { SNA- } \\
93\end{array}$ & $\begin{array}{c}1990 \text { a } 2005^{(1)}(12 S) \\
1990 \text { a } 2003(43 S)\end{array}$ & 1990 a 1994 \\
\hline $\begin{array}{l}2007 \mathrm{a} \\
2014\end{array}$ & IBGE & $\begin{array}{l}\text { Sistema de Contas } \\
\text { Nacionais } \\
\text { (SCN Ref. 2000) }\end{array}$ & IBGE (2011) & 2000 & $\begin{array}{l}\text { SNA- } \\
93\end{array}$ & $\begin{array}{c}1995 \text { a } 2013^{(1)}(12 S) \\
2000 \text { a } 2009(55 S)\end{array}$ & \\
\hline $\begin{array}{l}2015- \\
\text { atual }\end{array}$ & IBGE & $\begin{array}{l}\text { Sistema de Contas } \\
\text { Nacionais } \\
\text { (SCN Ref. 2010) } \\
\end{array}$ & $\begin{array}{l}\text { IBGE } \\
(2018 b)\end{array}$ & 2010 & $\begin{array}{l}\text { SNA- } \\
2008\end{array}$ & $\begin{array}{c}1995 \text { a } 2018^{(1)}(12 \mathrm{~S}) \\
2000-2016(51 \mathrm{~S}) \\
2010-2016(68 \mathrm{~S}) \\
\end{array}$ & 1995 - atual \\
\hline
\end{tabular}

(1) A agregação dos 12 setores provém das Contas Nacionais Trimestrais, sendo os últimos anos resultados preliminares. Fonte: IBGE (1990b, 2006) e Hallak Neto e Forte (2016). Adaptado pelo autor a partir de Hallak Neto e Forte (2016).

Por exemplo, o SCN Consolidadas ${ }^{6}$ possui informações anuais de 1947 a 1995 IBGE (1996, 2006), o SCN Ref. 1985 de 1990 a 2003 IBGE (2004a), e o SCN Ref. 2010 de 1995 a 2018 IBGE (2018a). Mas os resultados de apenas uma versão são considerados oficiais nos anos em que há sobreposição para compor a série da participação setorial no PIB, conforme exibido no Quadro 1 e nas linhas de cor preta (mais forte) do Gráfico 1.

\section{Gráfico 1 - Indústria de transformação (\% no PIB), Brasil, 1947-2017, preços correntes,} metodologias diferentes das Contas Nacionais

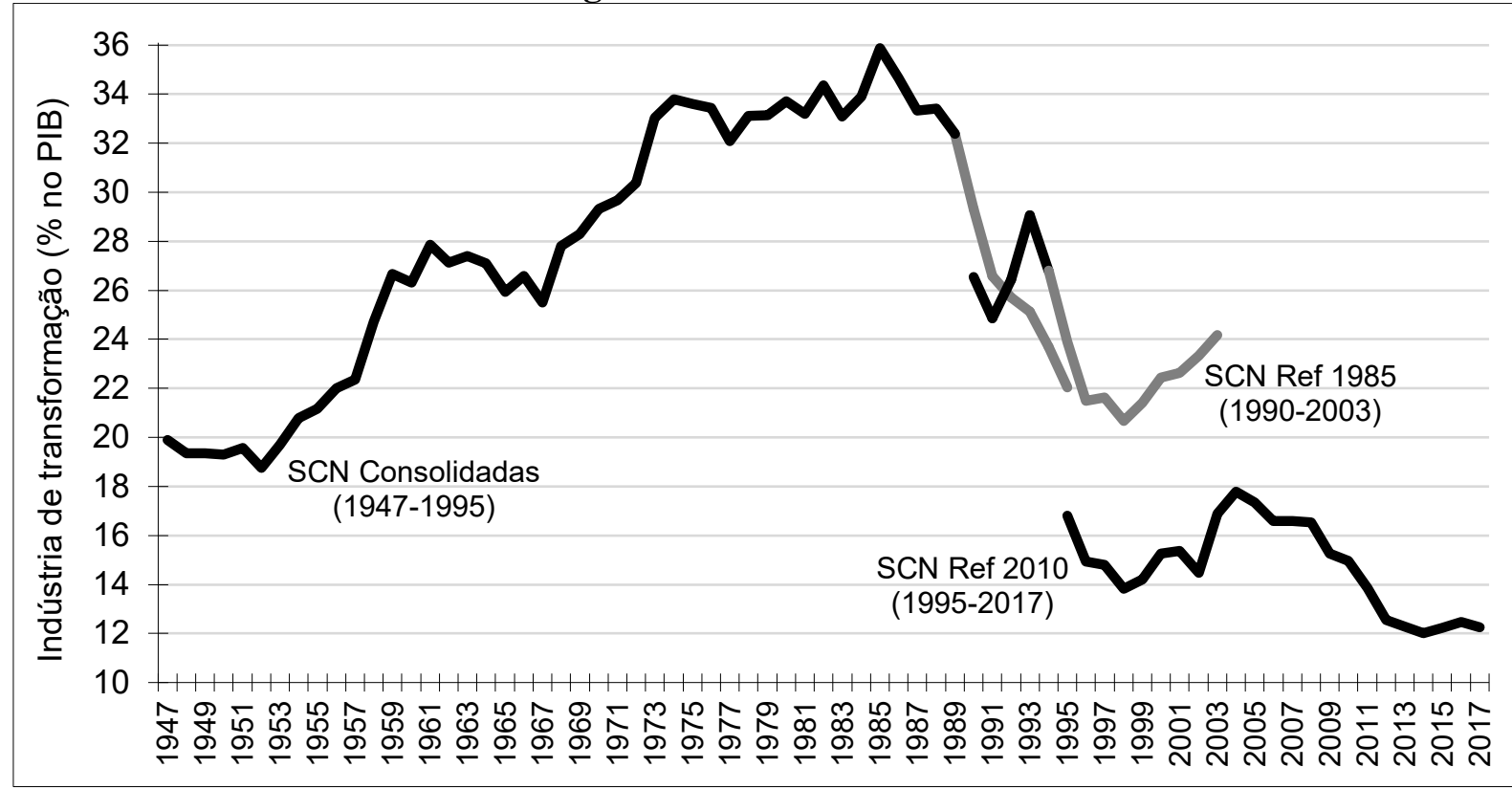

Nota: Linhas em cores pretas representam o período considerado oficial. PIB a custo de fatores no SCN Consolidadas e a preços básicos no SCN Ref. 1985 e no SCN Ref. 2010.

Fonte: IBGE (2004a, 2006, 2018a). Elaborado pelo autor.

O Gráfico 1 exibe a parcela do valor adicionado bruto (VAB) manufatureiro no PIB a custo de fatores ou a preços básicos por três SCN diferentes. Observa-se que, a cada divulgação de nova edição das

${ }^{6} \mathrm{O}$ SCN Consolidadas abrange o SCNC e as CCN do Quadro 1, os quais adotaram a mesma metodologia do IBGE (1990a). 
contas nacionais, a participação do setor manufatureiro no PIB diminuiu de 1947 a 2017 . A série oficial considera apenas as linhas exibida na cor preta do Gráfico 1.

No Gráfico 2 é possível notar duas quebras abruptas na série: uma entre 1989 e 1990 e outra entre 1994 e 1995. Os dados considerados oficiais para 1989 são do SCN Consolidadas e para 1990 do SCN Ref. 1985, essa mudança acarretou numa diminuição do peso da manufatura no PIB de 32,4\% para 26,5\%, uma queda de 5,9 p.p. A última queda é a mais abrupta. Os dados oficiais para 1994 são do SCN Ref. 1985 e para 1995, do SCN Ref. 2010, e neste intervalo a manufatura apresentou uma queda de 10 p.p. no PIB (de $26,8 \%$ para $16,8 \%$ ).

Ao observar apenas informações de uma versão das contas nacionais para os anos dessas quebras, nota-se que a parcela da manufatura no PIB diminuiu, porém numa intensidade muito menor. A partir do SCN Consolidadas, a manufatura diminuiu seu peso no PIB de 32,4\% para 29,3\%, entre 1989 e 1990 (Gráfico 1). E a partir do SCN Ref. 1985, a diminuição foi de 26,8\% para 23,9\% do PIB (Gráfico 1). Logo, o grau de industrialização deve ter tido uma diminuição muito menos abrupta do que as quebras de natureza metodológica sugerem.

Gráfico 2 - Série considerada oficial da indústria de transformação (\% no PIB), Brasil, 19472017, preços correntes, descontinuidades de natureza metodológica

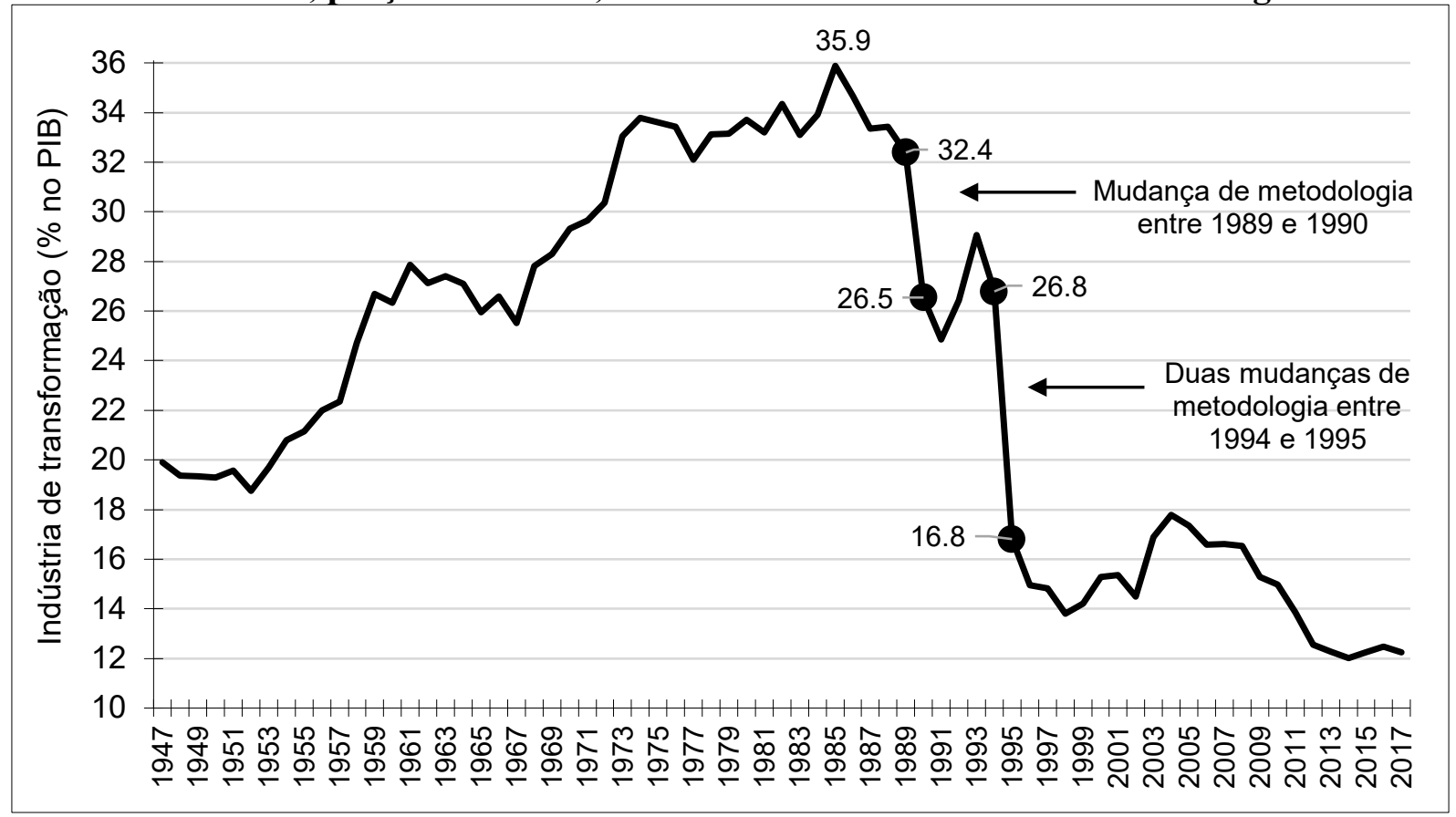

Fonte: IBGE (2004a, 2006, 2018a). Elaborado pelo autor.

O Gráfico 1 exibe séries da participação da manufatura no PIB mais longas que as documentadas pelos estudos sobre desindustrialização para o Brasil. Além disso, exibe séries com a mesma metodologia para os anos das descontinuidades metodológicas, de modo que se permite fazer uma análise da desindustrialização no período próximo ao destas descontinuidades. Note que pelo SCN Consolidadas o grau de industrialização apresentou forte redução desde 1985 até 1995 - sendo este o último ano da série -, em que a participação da manufatura no PIB diminuiu de 35,9\% para 22,0\%, respectivamente. Dessa maneira, a desindustrialização brasileira foi intensa tanto nos anos que antecederam a abertura comercial quanto durante a abertura. Já a série do SCN Ref. 1985, que cobre o período de 1990 a 2003, informa que a manufatura diminuiu sua participação de $26,5 \%$ para 20,7\%, entre 1990 e 1998. Este ano encerrou a primeira fase mais intensa da desindustrialização brasileira.

Observe também que há uma divergência no grau de industrialização nos anos de 1992 e 1993 ao comparar as séries do SCN Consolidadas e SCN Ref. 1985. O primeiro exibiu uma redução enquanto 
o segundo registrou aumento (Gráfico 1). Acreditamos que essa divergência se deve ao dummy financeiro que aumentou bastante em 1992 e 1993 nos resultados do SCN Ref. 1985.

O dummy financeiro influenciou o formato da série de participação da manufatura no PIB - ou de qualquer outro setor da economia -, sobretudo nos anos em que apresentou grande variabilidade (anos 1980 e primeira metade da década de 1990), conforme será explicado na próxima seção.

\subsection{PIB setorial sobrestimado devido ao Dummy Financeiro}

Vários estudos sobre mudança estrutural brasileira - seja pela abordagem da desindustrialização, do setor de serviços ou de outro setor da economia - exibem a distribuição setorial equivocada para o período anterior a 1995 ao utilizar dados do SCN Consolidadas (1947-1995) ou do SCN Ref. 1985 (1990-2003). Para se chegar ao peso que cada setor de atividade possui no PIB geralmente divide-se o valor adicionado bruto (VAB) de cada setor pelo PIB a custo de fatores ou a preços básicos. Essa divisão é incorreta porque o somatório do $\mathrm{VAB}$ de todos os setores da economia inclui os serviços de intermediação financeira indiretamente medidos (SIFIM), porém o PIB a custo de fatores ou a preços de básicos exclui os SIFIM. Esta variável corresponde à diferença entre os juros recebidos e juros pagos, que pode ter incidido em qualquer um dos setores de atividade. Dessa maneira, a participação setorial no PIB está sobrestimada na magnitude da contribuição de cada setor para o dummy financeiro.

Os SIFIM deveriam ser embutidos no consumo intermediário de todas as atividades produtivas, desse modo, diminuindo o VAB (dado que o VAB corresponde ao valor da produção excluído o consumo intermediário). Mas não são. Assim, todos os setores de atividade possuem VAB maior porque os pagamentos com SIFIM não foram descontados do VAB setorial. Assim, para se obter o PIB a custo de fatores ou a preços básicos no agregado da economia, o IBGE criou um setor fíctício denominado dummy financeiro com VAB negativo na mesma magnitude dos SIFIM - este setor tem produção nula e consumo intermediário igual ao valor dos SIFIM. Em síntese, o PIB a custo de fatores no SCN Consolidadas e o PIB a preços básicos no SCN Ref. 1985 estão corretos para o agregado da economia, mas o VAB setorial está sobrestimado.

A Tabela 1 exibe a distribuição do valor adicionado de cada setor pela metodologia do SCN Consolidadas e a Tabela 2 pela metodologia do SCN Ref. 1985 . $^{7}$ Note que a soma de todos os setores que formam a economia ultrapassa $100 \%$ em todos os anos. Verifiquemos um exemplo. Em 1985, conforme documentado pela literatura, a participação da indústria de transformação alcançou seu percentual máximo de 35,9\% do PIB brasileiro, no mesmo ano a agropecuária obteve 12,6\% do PIB, o agregado formado pelas outras indústrias obteve $12,1 \%$ e serviços $52,9 \%$, totalizando $113,5 \%$. Logo, a manufatura obteve $35,9 \%$ de um subtotal de $113,5 \%$, não de $100 \%$ como base de comparação. Da forma como é calculada a participação dos setores no PIB, em 1985 a sobre-estimação de todos os setores foi de $13,5 \%$ do PIB. Em 1989, foi de 26,5\%, sendo que apenas a parcela da indústria de transformação e a dos serviços já ultrapassa $100 \%$ neste ano (Tabela 1). Isto se deve ao dummy financeiro.

Tais evidências colocam em relevo a tese da sobre-industrialização levantada por Bonelli e Pessôa (2010), pois pode-se questionar se a sobre-industrialização não se deve, ao menos em parte, a sobreestimação da participação da manufatura no PIB brasileiro.

\section{Tabela 1 - Participação percentual dos agregados econômicos no PIB (a custo de fatores) a partir das Contas Consolidadas, 1947-1995}

\footnotetext{
${ }^{7}$ Para a indústria de transformação, os percentuais exibidos nas Tabelas 1 e 2 são os mesmos que foram apresentados nos Gráficos 1 e 2 da seção anterior.
} 


\begin{tabular}{|c|c|c|c|c|c|c|c|}
\hline & Agropecuária & $\begin{array}{c}\text { Outras } \\
\text { indústrias }\end{array}$ & $\begin{array}{c}\text { Indústria de } \\
\text { transformação }\end{array}$ & Serviços & SUBTOTAL & $\begin{array}{c}\text { Dummy } \\
\text { Financeiro }\end{array}$ & $\begin{array}{c}\text { PIB a custo } \\
\text { de fatores }\end{array}$ \\
\hline 1947 & 21,4 & 6,1 & 19,9 & 55,7 & 103,1 & $-3,0$ & 100,0 \\
\hline 1948 & 23,4 & 5,5 & 19,4 & 54,6 & 102,9 & $-2,9$ & 100,0 \\
\hline 1949 & 24,2 & 6,0 & 19,4 & 53,0 & 102,6 & $-2,6$ & 100,0 \\
\hline 1950 & 25,1 & 5,7 & 19,3 & 53,3 & 103,3 & $-3,3$ & 100,0 \\
\hline 1951 & 24,6 & 6,4 & 19,6 & 52,8 & 103,4 & $-3,4$ & 100,0 \\
\hline 1952 & 25,8 & 6,2 & 18,8 & 52,5 & 103,3 & $-3,3$ & 100,0 \\
\hline 1953 & 24,4 & 6,6 & 19,7 & 52,8 & 103,4 & $-3,4$ & 100,0 \\
\hline 1954 & 25,0 & 5,9 & 20,8 & 51,9 & 103,6 & $-3,6$ & 100,0 \\
\hline 1955 & 24,3 & 5,4 & 21,2 & 52,8 & 103,7 & $-3,7$ & 100,0 \\
\hline 1956 & 21,8 & 6,2 & 22,0 & 53,3 & 103,4 & $-3,4$ & 100,0 \\
\hline 1957 & 21,2 & 6,5 & 22,4 & 53,7 & 103,8 & $-3,8$ & 100,0 \\
\hline 1958 & 19,0 & 7,4 & 24,7 & 52,2 & 103,3 & $-3,3$ & 100,0 \\
\hline 1959 & 17,7 & 7,3 & 26,7 & 51,3 & 102,9 & $-2,9$ & 100,0 \\
\hline 1960 & 18,3 & 6,9 & 26,3 & 51,5 & 103,0 & $-3,0$ & 100,0 \\
\hline 1961 & 17,5 & 5,7 & 27,9 & 52,0 & 103,1 & $-3,1$ & 100,0 \\
\hline 1962 & 18,0 & 6,4 & 27,1 & 51,7 & 103,4 & $-3,4$ & 100,0 \\
\hline 1963 & 16,5 & 6,8 & 27,4 & 52,6 & 103,3 & $-3,3$ & 100,0 \\
\hline 1964 & 16,9 & 6,6 & 27,1 & 53,0 & 103,6 & $-3,6$ & 100,0 \\
\hline 1965 & 16,5 & 7,3 & 25,9 & 54,3 & 104,0 & $-4,0$ & 100,0 \\
\hline 1966 & 14,8 & 7,6 & 26,6 & 55,4 & 104,4 & $-4,4$ & 100,0 \\
\hline 1967 & 14,3 & 7,9 & 25,5 & 56,7 & 104,4 & $-4,4$ & 100,0 \\
\hline 1968 & 12,3 & 8,5 & 27,8 & 55,9 & 104,5 & $-4,5$ & 100,0 \\
\hline 1969 & 11,9 & 8,6 & 28,3 & 55,8 & 104,6 & $-4,6$ & 100,0 \\
\hline 1970 & 12,3 & 9,0 & 29,3 & 56,2 & 106,9 & $-6,9$ & 100,0 \\
\hline 1971 & 13,0 & 9,2 & 29,7 & 55,3 & 107,2 & $-7,2$ & 100,0 \\
\hline 1972 & 13,1 & 9,1 & 30,4 & 54,2 & 106,8 & $-6,8$ & 100,0 \\
\hline 1973 & 12,6 & 8,9 & 33,0 & 51,3 & 105,9 & $-5,9$ & 100,0 \\
\hline 1974 & 12,2 & 9,4 & 33,8 & 51,2 & 106,6 & $-6,6$ & 100,0 \\
\hline 1975 & 11,5 & 9,7 & 33,6 & 52,4 & 107,2 & $-7,2$ & 100,0 \\
\hline 1976 & 11,7 & 9,6 & 33,4 & 53,1 & 107,8 & $-7,8$ & 100,0 \\
\hline 1977 & 13,6 & 9,7 & 32,1 & 52,7 & 108,1 & $-8,1$ & 100,0 \\
\hline 1978 & 11,2 & 10,0 & 33,1 & 54,8 & 109,1 & $-9,1$ & 100,0 \\
\hline 1979 & 10,8 & 10,4 & 33,1 & 54,4 & 108,8 & $-8,8$ & 100,0 \\
\hline 1980 & 10,9 & 10,4 & 33,7 & 52,7 & 107,7 & $-7,7$ & 100,0 \\
\hline 1981 & 11,2 & 11,1 & 33,2 & 55,2 & 110,7 & $-10,7$ & 100,0 \\
\hline 1982 & 9,7 & 11,4 & 34,4 & 55,6 & 111,1 & $-11,1$ & 100,0 \\
\hline 1983 & 12,5 & 11,3 & 33,1 & 57,1 & 113,9 & $-13,9$ & 100,0 \\
\hline 1984 & 13,8 & 12,3 & 33,9 & 53,5 & 113,5 & $-13,5$ & 100,0 \\
\hline 1985 & 12,6 & 12,1 & 35,9 & 52,9 & 113,5 & $-13,5$ & 100,0 \\
\hline 1986 & 12,1 & 12,5 & 34,7 & 48,7 & 108,0 & $-8,0$ & 100,0 \\
\hline 1987 & 10,8 & 14,2 & 33,3 & 57,6 & 115,9 & $-15,9$ & 100,0 \\
\hline 1988 & 11,4 & 13,3 & 33,4 & 58,6 & 116,8 & $-16,8$ & 100,0 \\
\hline 1989 & 9,8 & 14,0 & 32,4 & 70,4 & 126,5 & $-26,5$ & 100,0 \\
\hline 1990 & 11,6 & 12,6 & 29,3 & 60,6 & 114,2 & $-14,2$ & 100,0 \\
\hline 1991 & 11,5 & 11,8 & 26,6 & 62,0 & 111,9 & $-11,9$ & 100,0 \\
\hline 1992 & 12,2 & 12,6 & 25,7 & 62,6 & 113,1 & $-13,1$ & 100,0 \\
\hline 1993 & 12,4 & 12,8 & 25,1 & 66,1 & 116,4 & $-16,4$ & 100,0 \\
\hline 1994 & 14,2 & 12,4 & 23,7 & 62,4 & 112,8 & $-12,8$ & 100,0 \\
\hline 1995 & 12,2 & 11,6 & 22,0 & 61,2 & 107,0 & $-7,0$ & 100,0 \\
\hline
\end{tabular}

Fonte: IBGE (1996, 2006). Elaborado pelo autor.

Tabela 2 - Participação percentual dos agregados econômicos no PIB (a preços básicos) a partir do Sistema de Contas Nacionais Referência 1985, 1990-2003 


\begin{tabular}{cccccccc}
\hline Agropecuária & $\begin{array}{c}\text { Outras } \\
\text { indústrias }\end{array}$ & $\begin{array}{c}\text { Indústria de } \\
\text { transformação }\end{array}$ & Serviços & SUBTOTAL & $\begin{array}{c}\text { Dummy } \\
\text { Financeiro }\end{array}$ & $\begin{array}{c}\text { PIB a custo } \\
\text { de fatores }\end{array}$ \\
\hline 1990 & 8,1 & 12,1 & 26,5 & 70,3 & 117,1 & $-17,1$ & 100,0 \\
1991 & 7,8 & 11,3 & 24,9 & 68,9 & 112,9 & $-12,9$ & 100,0 \\
1992 & 7,7 & 12,3 & 26,4 & 77,5 & 123,9 & $-23,9$ & 100,0 \\
1993 & 7,6 & 12,5 & 29,1 & 81,8 & 131,0 & $-31,0$ & 100,0 \\
1994 & 9,9 & 13,2 & 26,8 & 64,3 & 114,1 & $-14,1$ & 100,0 \\
1995 & 9,0 & 12,8 & 23,9 & 60,7 & 106,4 & $-6,4$ & 100,0 \\
1996 & 8,3 & 13,2 & 21,5 & 62,3 & 105,3 & $-5,3$ & 100,0 \\
1997 & 8,0 & 13,6 & 21,6 & 61,9 & 105,1 & $-5,1$ & 100,0 \\
1998 & 8,2 & 13,9 & 20,7 & 62,3 & 105,1 & $-5,1$ & 100,0 \\
1999 & 8,3 & 14,2 & 21,4 & 60,9 & 104,7 & $-4,7$ & 100,0 \\
2000 & 8,0 & 15,1 & 22,4 & 58,5 & 104,0 & $-4,0$ & 100,0 \\
2001 & 8,4 & 15,1 & 22,6 & 59,0 & 105,1 & $-5,1$ & 100,0 \\
2002 & 8,7 & 15,0 & 23,3 & 59,2 & 106,3 & $-6,3$ & 100,0 \\
2003 & 9,9 & 14,6 & 24,2 & 56,7 & 105,3 & $-5,3$ & 100,0 \\
\hline
\end{tabular}

Fonte: IBGE (2004a). Elaborado pelo autor.

O problema causado pelo dummy financeiro é que ele oscilou e aumentou bastante desde início dos anos 1980 até meados da década seguinte, influenciando o formato da série de participação setorial no PIB. Nos anos em que houve uma grande oscilação - como entre 1988 e 1989 (Tabela 1) ou entre 1991 e 1992 (Tabela 2) - fica difícil interpretar se a participação setorial no PIB se deve ao comportamento setorial ou ao dummy financeiro. De qualquer forma, em algum grau o formato da série de participação setorial no PIB será contaminado pelo dummy financeiro.

O leitor atento pode questionar se, ao menos em parte, a participação setorial no PIB está correlacionada ao dummy financeiro. Fizemos a correlação de Pearson entre a participação no PIB da indústria de transformação e o dummy financeiro, exibida na Tabela 3. Para todo o período coberto pelo SCN Consolidadas a correlação foi de 0,55 e para todo o período coberto pelo SCN Ref. 1985 foi de 0,90. Essa correlação aumenta para o período considerado oficial na série de (des)industrialização. Ao considerar apenas o período da desindustrialização, a partir de 1985, observa-se que a correlação foi de $-0,75 \%$ para o período de 1985 a 1989 pelo SCN Consolidadas e de $-0,83 \%$ para o período de 1990 a 1994 pelo SCN Ref. 1985.

Provavelmente, o formato da série de (des)industrialização é distinto do exibido em vários estudos, sobretudo para os anos em que houve grande oscilação no dummy financeiro. Também é possível que a participação da indústria de transformação no PIB não tenha aumentado nos anos de 1992 e 1993 (como ocorreu no SCN Ref. 1985), mas que tenha caído como ocorreu no SCN Consolidadas, e a diminuição da parcela manufatureira tenha sido mais intensa na segunda metade dos anos 1980.

Tabela 3 - Correlação de Pearson entre a participação no PIB da indústria de transformação e do dummy financeiro

\begin{tabular}{lcc}
\hline & SCN Consolidadas & SCN Ref. 1985 \\
\hline 1947-1995 (período todo) & 0,55 & 0,90 \\
$1990-2003$ (período todo) & & 0,67 \\
1947-1989 (período considerado oficial da série de (des)industrialização) & 0,83 \\
1990-1994 (período considerado oficial da série de (des)industrialização) & & \\
$1985-1989$ (período inicial da redução da participação industrial no PIB) & $-0,75$ & \\
\hline
\end{tabular}

Fonte: IBGE (2004a, 2006). Cálculos e elaboração do autor.

Para se obter a participação correta de cada setor no PIB o ideal seria eliminar o dummy financeiro nas Contas Nacionais antigas como realizado nas Contas Nacionais modernas, no entanto, isso não é possível segundo o IBGE. Nas Contas Nacionais mais antigas - SCN Consolidadas e SCN Ref. 1985 - o IBGE afirma que não tinha "(...) uma metodologia conceitualmente satisfatória do ponto de vista econômico e para qual os dados requeridos estejam disponíveis (...)" para identificar a contribuição 
de cada setor de atividade para o dummy financeiro (IBGE, 2004b, p. 36). O dummy financeiro só foi eliminado a partir do SCN Ref. 2000 (IBGE, 2008).

A próxima seção apresenta um método alternativo para distribuir o dummy financeiro e fazer que a soma das parcelas setoriais no PIB seja 100\%. Além disso, ela também exibe fórmulas facilmente de serem replicadas para encadear as séries de participação setorial no PIB de modo a contornar as duas quebras metodológicas mencionadas na seção 3.1.

\section{Métodos propostos para corrigir as quebras metodológicas na série de participação da indústria de transformação no PIB e eliminar o problema do Dummy Financeiro}

Esta seção apresenta dois métodos que visam eliminar as descontinuidades metodológicas e corrigir o problema da sobrestimação causada pelo dummy financeiro.

A correção da série será proposta de duas formas diferentes. A primeira - que chamaremos de método $I$ (ou método tradicional) - corrige as já mencionadas quebras entre 1989 e 1990 e entre 1994 e 1995

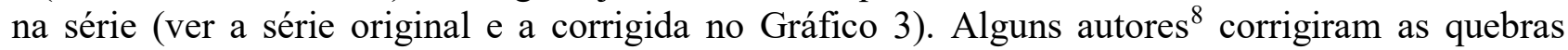
mencionadas, mas não deixaram claro como foi feito o encadeamento das séries. O método 1 abaixo explica o procedimento passo a passo.

No entanto, apesar dos ajustes para eliminar as quebras metodológicas (conforme exibido no Gráfico 3), a participação da indústria de transformação no PIB foi corrigida com base em pesos errados devido ao problema do dummy financeiro mencionado na seção anterior. Por isso, propomos a segunda forma - que chamaremos de método 2 -, que além de eliminar as quebras metodológicas, também corrige o problema da dummy financeiro (ver Gráfico 4).

\subsection{Método 1: correção das descontinuidades metodológicas}

A série oficial utiliza o peso da participação da manufatura no PIB do período de 1947 a 1989 do SCN Consolidadas, de 1990-1994 do SCN Ref. 1985, e de 1995-2017 do SCN Ref. 2010. Surgem, portanto, duas quebras na série: (i) a primeira de 5,9 p.p., quando a parcela da indústria no PIB reduziu-se de 32,4\% no SCN Consolidadas para 26,5\% no SCN Ref. 1985 entre 1989 e 1990; e (ii) a segunda de 10,0 p.p., pois a parcela da indústria no PIB diminuiu de 26,8\% no SCN Ref. 1985 para 16,8\% no SCN Ref. 2010 entre 1994 e 1995 (ver Gráfico 3).

Para corrigir essas duas descontinuidades, a fórmula abaixo informa como foi ajustada a série de 1947 a 1994 para refletir a metodologia atual do IBGE, pois de 1995 a 2018 manteve-se a mesma série do SCN Ref. 2010.

$$
P_{t-1}^{a}=\left(\frac{P_{t-1}^{m a}}{P_{t}^{m a}}\right) P_{t}^{a}
$$

Em que $P=$ participação percentual da indústria de transformação no PIB a preços básicos ou a custo de fatores; sobrescrito $a$ indica metodologia atual do SCN Ref. 2010 ou compatível; sobrescrito ma indica metodologia antiga (SCN Consolidadas de 1947-1990 e SCN Ref. 1985 de 1990-1995); e o subscrito $t$ é o ano, de 1947 a 1995. O termo dentro dos parênteses em (1) é o fator de ajuste que considera a mesma variação percentual interanual do resultado divulgado na metodologia antiga. Foi utilizado o SCN Ref. 1985 para obter o fator ajuste para anos de 1990 a 1994, e o SCN Consolidadas para obter o fator ajuste para anos 1947 a 1989. Assim, aplica-se a fórmula (1) para obter a participação setorial no PIB anual, retroativamente, de 1994 a 1947.

\footnotetext{
${ }^{8}$ Por exemplo, Bonelli e Pessôa (2010), Morceiro (2012), Fiesp (2013), Bonelli, Pessôa e Matos (2013) e FIESP e CIESP (2018).
} 
Gráfico 3 - Indústria de transformação (\% do PIB), Brasil, 1947-2017, a preços correntes, série original e série corrigida pelo método tradicional

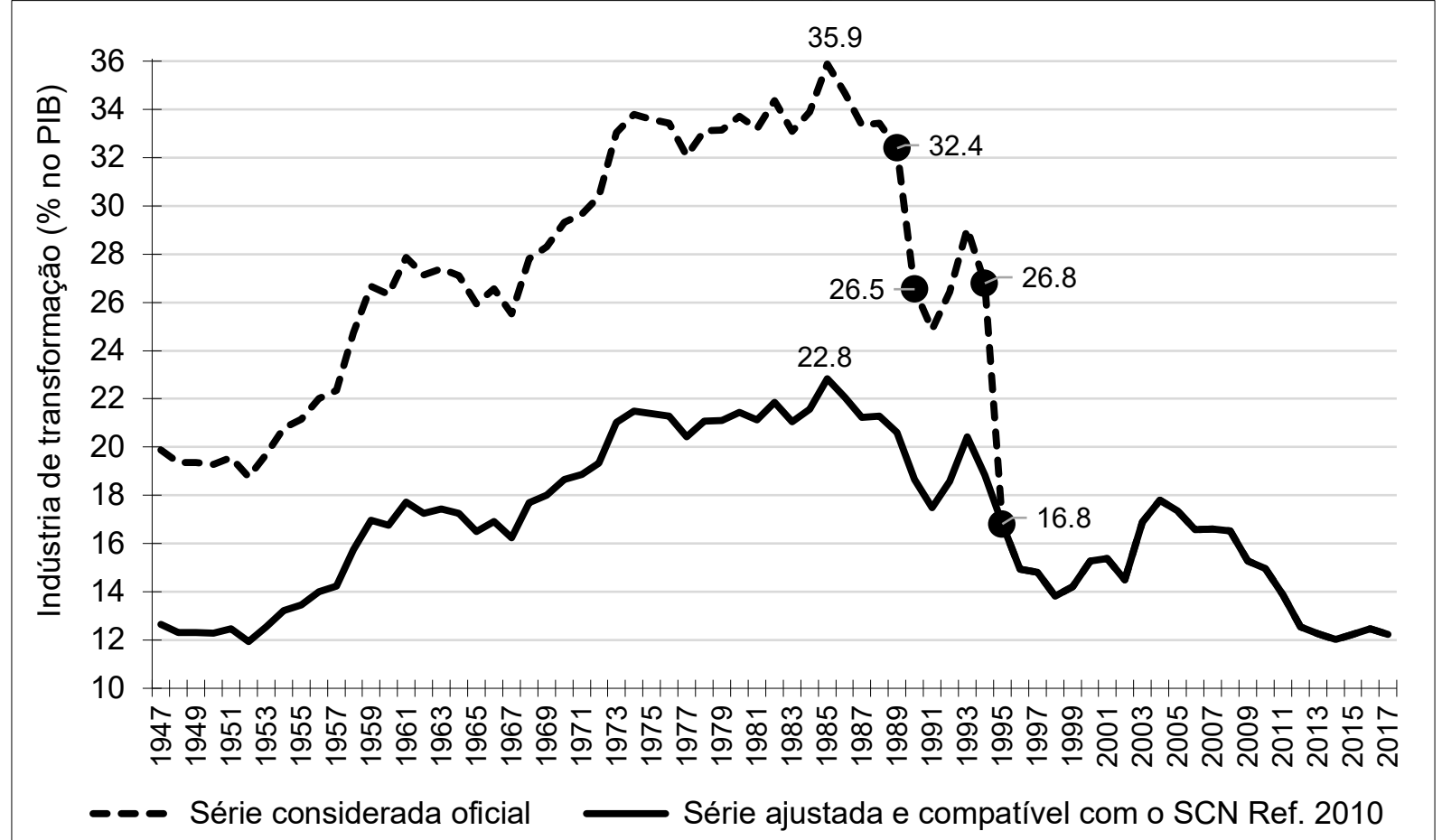

Nota: PIB a custo de fatores de 1947 a 1989 e a preços básicos de 1990 a 2017. SCN Consolidadas para o período 1947-1989, SCN Ref. 1985 para o período 1990-1994 e SCN Ref. 2010 para o período 1995-2017.

Fonte: IBGE (1994, 1996, 2004a, 2006, 2016, 2018a). Cálculos e elaboração do autor.

Ressalta-se, mais uma vez, que para o período de 1995 a 2017 adotamos o mesmo peso da manufatura no PIB do SCN Ref. 2010. Assim, ao aplicar fórmula (1) para o ano de 1994, tem-se:

$P_{1994}^{a}=\left(\frac{P_{1994}^{m a}}{P_{1995}^{m a}}\right) P_{1995}^{a}=\left(\frac{26,8 \%}{23,9 \%}\right) 16,8 \%=18,8 \%$

Então, para 1994 a participação percentual da manufatura no PIB foi de $18,8 \%$ compatível com o SCN Ref. 2010. Desse modo, entre 1994 e 1995, a indústria de transformação diminuiu 2 p.p. (ou $10,7 \%$ ), de 18,8\% para 16,8\% na metodologia atual do SCN Ref. 2010 ou compatível com esta metodologia. ${ }^{9}$ Ao aplicar a fórmula (1) para todos os anos obtém-se a série ajustada e compatível com o SCN Ref. 2010 exibida no Gráfico 3. Observe que a série corrigida segue o mesmo formato da série original devido ao fator de ajuste captar a mesma variação percentual na série original e na série corrigida. O pico da manufatura também foi em 1985 na série corrigida ao atingir 22,8\% do PIB.

\subsection{Método 2: correção da dummy financeiro e das descontinuidades metodológicas}

A série considerada oficial e a série corrigida, exibidas no Gráfico 3, são muito utilizadas no diagnóstico de desindustrialização do Brasil. No entanto, utilizar a participação setorial no PIB sem distribuir setorialmente o dummy financeiro pode interferir no formato e nível da série de participação dos setores no PIB.

Ressaltamos que em 1985, a participação da manufatura no PIB alcançou o seu pico de 35,9\%; ano em que a soma de todos os setores no PIB somou 113,5\% porque o dummy financeiro equivaleu a 13,5\% do PIB. Em alguns anos, conforme dados da seção 3.2, o dummy financeiro superou um quarto do PIB: em 1989, foi 26,5\% no SCN Consolidadas e em 1993 alcançou 31,0\% no SCN Ref. 1985.

\footnotetext{
${ }^{9}$ Observe que entre 1994 e 1995 encontra-se a mesma variação percentual de 10,7\% com dados do SCN Ref. 1985.
} 
Desse modo, nos anos em que houve grande variação no dummy financeiro é provável que também tenha havido grande variação, na mesma direção, da participação setorial no PIB.

Para averiguar se o problema causado pelo dummy financeiro continuou na série corrigida pelo método 1, este estudo aplicou este método para os demais setores da economia. Assim, o método 1 foi aplicado para quatro setores da economia - a saber, agropecuária, indústria de transformação, outras indústrias ${ }^{10}$ e serviços - e foi verificado que a soma das participações desses quatro setores variou bastante ao longo dos anos, de $95,6 \%$ a $126,1 \%$; uma diferença muito grande de 30,5 p.p. do PIB. Logo, os autores ${ }^{11}$ que realizaram o ajuste na série de participação da manufatura no PIB pelo método 1 não levaram em conta que se repetisse o mesmo procedimento para os demais setores da economia a soma ultrapassa em muito $100 \%$ e essa sobrestimação do PIB se deve majoritariamente ao dummy financeiro não ter sido eliminado nas Conta Nacionais antigas. Dessa maneira, a série corrigida para a indústria de transformação exibida no Gráfico 3 não é consistente com o total da economia e não pode ser comparada com qualquer outro setor da economia que utilize a mesma correção. Certamente, ao eliminar a sobrestimação causada pelo dummy financeiro a participação setorial no PIB se alterará.

Considere as duas fórmulas a seguir para entender o problema:

$$
\begin{aligned}
& P I B_{\text {cf ou } p b}=S_{1}+S_{2}+\cdots+S_{n}-D F=100 \% \\
& P I B_{\text {cf ou } p b}=S_{1}+S_{2}+\cdots+S_{n}=100 \%+D F
\end{aligned}
$$

Em que $P I B_{c f \text { ou } p b}$ é o PIB da economia de um determinado ano valorado a custo de fatores ou a preços básicos normalizado em 100\%. O SCN Consolidadas e o SCN Ref. 1985 adotaram o dummy financeiro (DF), o primeiro valorou o PIB a custo de fatores e o segundo a preços básicos. $S$ é a participação percentual setorial no PIB incluindo o dummy financeiro do setor em questão, na economia com $1,2, \ldots ., n$ setores. Ao usar a participação percentual setorial no PIB sem eliminar o DF, conforme exibido em (4), a participação setorial estará sobrestimada porque cada um dos setores contém o valor adicionado setorial mais os SIFIM (isto é, o dummy financeiro incidente em cada setor). Os estudos sobre desindustrialização no Brasil utilizam a participação setorial no PIB conforme a fórmula (4), assim, as somas setoriais ultrapassam $100 \%$.

A medida ideal deveria distribuir o dummy financeiro na mesma proporção em que cada setor tenha contribuído para ele, contudo ainda não é possível porque não há informações disponíveis e nem consenso metodológico, conforme exposto pelo IBGE (2004b, p. 36). Assim, propõe-se aqui uma forma alternativa e pragmática para realizar tal distribuição. A fórmula (5) a seguir exibe os pesos percentuais que cada setor possui no PIB a custo de fatores ou preços básicos já com o dummy financeiro distribuído (o sobrescrito $d$ indica a distribuição).

$P I B_{\text {cf ou pb }}=S_{1}^{d}+S_{2}^{d}+\ldots+S_{n}^{d}=100 \%$

Em que $S_{1}^{d}$ e $S_{2}^{d}$ são:

\footnotetext{
${ }^{10}$ Outras indústrias incluem indústria extrativa, construção civil e serviços industriais de utilidade pública.

${ }^{11}$ Conferir os autores citados na nota de rodapé 8 .
} 
$S_{1}^{d}=\frac{S_{1}}{P I B_{\text {cf ou } p \text { b }}+D F} \quad, \quad S_{2}^{d}=\frac{S_{2}}{P I B_{\text {cf ou } p b}+D F}$

$(6)^{12}$

Assim, a primeira etapa do método 2 refere-se à distribuição do dummy financeiro acima. O Gráfico 4 exibe a série de participação da indústria de transformação no PIB com a distribuição do dummy financeiro, de 1947 a 1994.

\section{Gráfico 4 - Indústria de transformação (\% do PIB), Brasil, 1947-2017, a preços correntes,} com distribuição do Dummy Financeiro e nova série corrigida

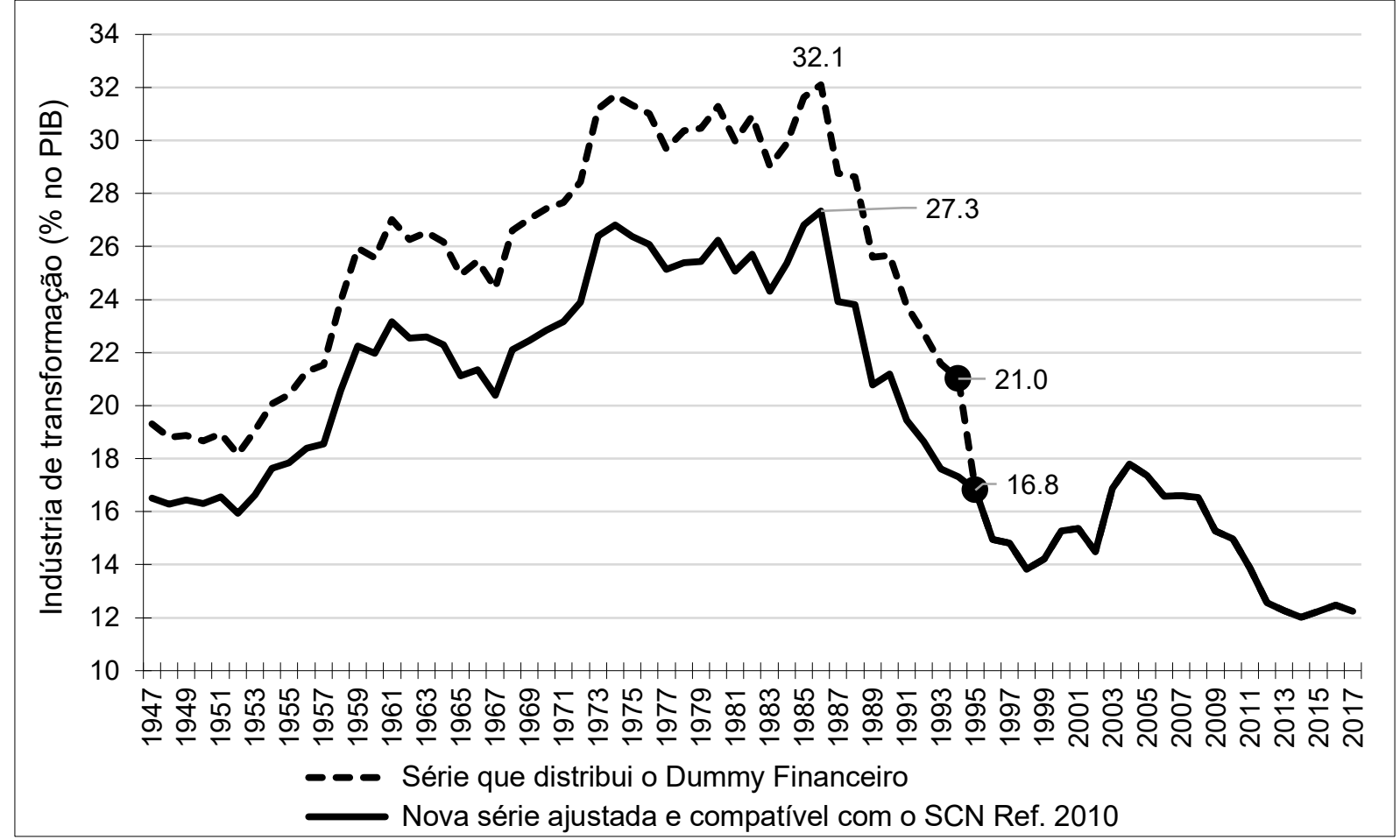

Nota: PIB a custo de fatores de 1947 a 1994 e a preços básicos de 1995 a 2017. SCN Consolidadas para o período 1947-1994 e SCN Ref. 2010 para o período 1995-2017.

Fonte: IBGE (1996, 2006, 2018a). Cálculos e elaboração do autor.

Para a segunda etapa do método 2 utiliza-se apenas Contas Nacionais ao invés de três como feito método 1: SCN Consolidadas de 1947 a 1995 e SCN Ref. 2010 a partir de 1995, que são as Contas Nacionais mais extensas que o Brasil possui. Optou-se por não utilizar o SCN Ref. 1985 para o período de 1990 a 1994 porque o dummy financeiro apresentou elevada variabilidade neste período comparativamente ao SCN Consolidadas. ${ }^{13}$ Outra vantagem é lidar com apenas uma descontinuidade metodológica (entre 1994 e 1995).

Basta aplicar a fórmula (1) do método 1 para obter a participação percentual setorial no PIB de determinado ano entre 1947 a 1994, e se atentar para utilizar a participação setorial com o dummy financeiro distribuído em (5) no fator de ajuste. Assim, para 1994 temos:

$P_{1994}^{a}=\left(\frac{P_{1994}^{m a}}{P_{1995}^{m a}}\right) P_{1995}^{a}=\left(\frac{21,0 \%}{20,6 \%}\right) 16,8 \%=17,1 \%$

12 Observe que o dummy financeiro atribuído ao setor 1 e ao setor 2 é, respectivamente, $D F_{1}=\left(\frac{S_{1}}{P I B_{c f} \text { ou } p b^{+D F}}\right) D F$ e $D F_{2}=\left(\frac{S_{2}}{P I B_{\text {cf ou } p b^{+D F}}}\right) D F$. Assim, outra maneira de se obter a participação percentual do setor 1 sem o dummy financeiro

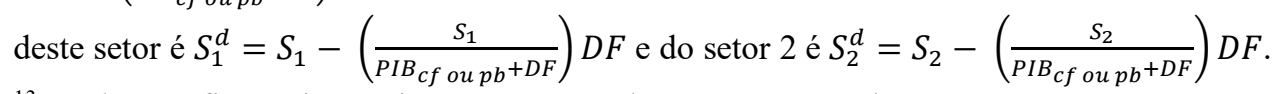

${ }^{13} \mathrm{O}$ dummy financeiro variou entre 6,4\% do PIB e 31,0\% do PIB entre 1990 e 1995 no SCN Ref. 1985. No mesmo período pelo SCN Consolidado, variou entre $7,0 \%$ e $16,4 \%$ do PIB. 
O termo em parênteses em (7) é o fator de ajuste que considera a variação percentual interanual com o dummy financeiro distribuído. Como feito antes, aplica-se a fórmula 7 para obter a participação setorial no PIB anual, retroativamente, de 1994 a 1947.

A partir de (7), verifica-se que em 1994 a participação da manufatura no PIB foi de 17,1\% compatível com o SCN Ref. 2010. Além da indústria de transformação, a fórmula (7) foi aplicada para os demais setores que compõem a economia total, a saber, agropecuária, outras indústrias e setor de serviços. Faz-se essa análise de acuidade para verificar se o total está por volta de $100 \%$. Como resultado, os quatro setores somaram 99,0\% do PIB em 1994. Para os demais anos, a soma variou entre 92,9\% e 100,6\% do PIB, respectivamente em 1954 e 1989, ou seja, uma diferença de no máximo 7,1 p.p. do PIB que chamaremos de resíduo. ${ }^{14}$

A seguir distribui-se setorialmente o resíduo utilizando como pesos a mesma participação setorial obtida em (7). Para 1994 o resíduo foi de 1,0 p.p. do PIB, conforme o parágrafo acima. Assim, pelo método 2, a participação final da indústria de transformação para 1994, já compatibilizada para o SCN Ref. 2010 , foi $17,3 \%$ do PIB $-17,1 \%$ obtida em (7) $+17,1 \%$ x 1,0\% $=0,2 \%$ da distribuição do resíduo).

Após aplicar (7) para todos os anos e distribuir proporcionalmente o resíduo, obtém-se a distribuição setorial final em porcentagem do PIB compatível com o SCN Ref. 2010 (Gráfico 5). A nova série ajustada e compatível com o SCN Ref. 2010 para a indústria de transformação pode ser visualizada tanto no Gráfico 4 quanto no Gráfico 5.

\section{Gráfico 5 - Distribuição setorial (em \% do PIB), Brasil, 1947 a 2017, a preços correntes}

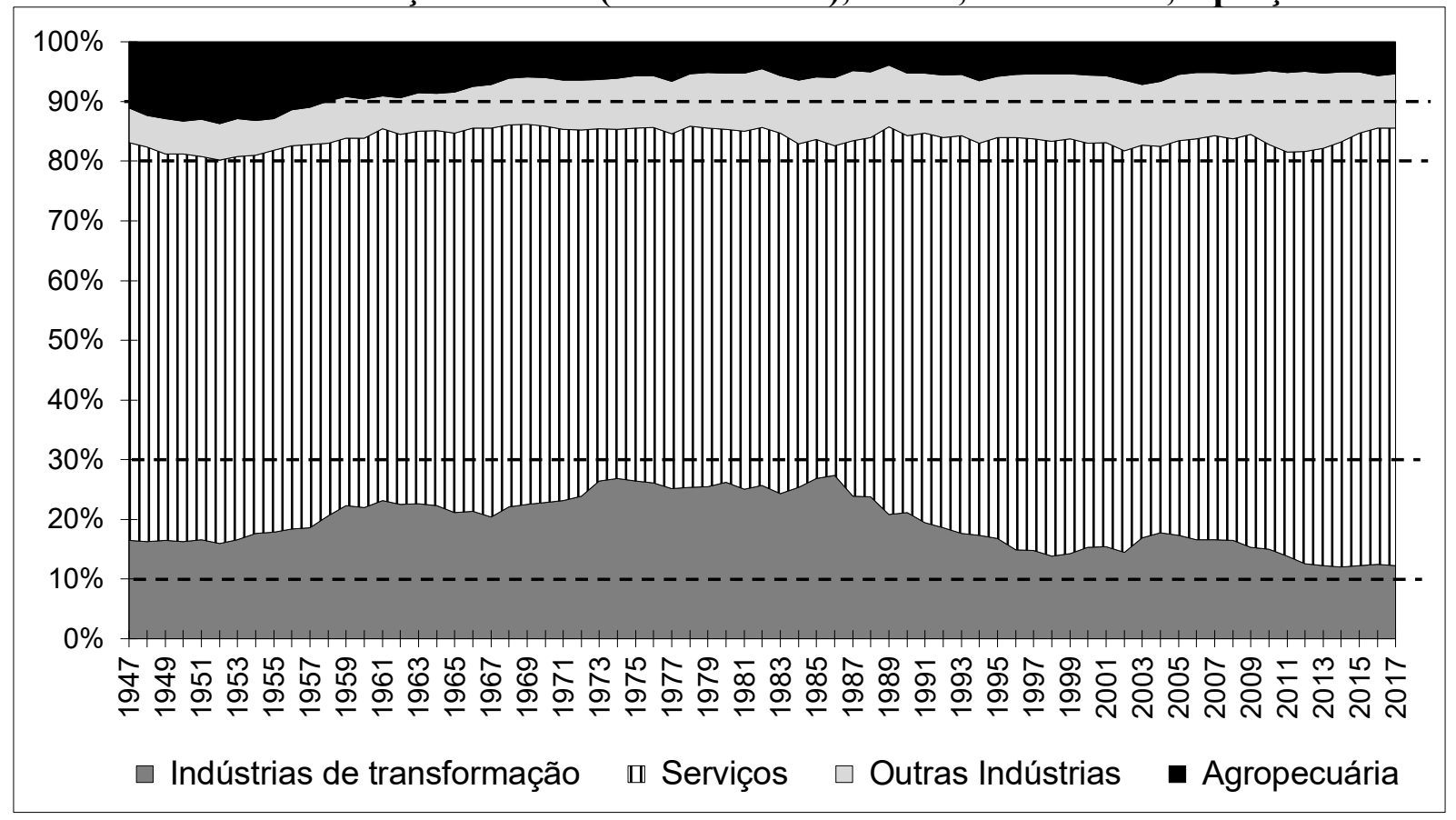

Nota: Séries setoriais ajustadas e compatível com o SCN Ref. 2010.

Fonte: IBGE (1996, 2006, 2018a). Cálculos e elaboração próprios.

Nas últimas sete décadas o setor de serviços dominou a economia brasileira com participação no PIB superior a 50\% (Gráfico 5). O menor percentual foi em 1986, (55,3\% do PIB), no mesmo ano, a indústria de transformação alcançou seu pico (27,3\%). A redução relativa do setor manufatureiro foi absorvida pelo setor de serviços: enquanto a manufatura perdeu 15,1 p.p. do PIB entre 1986 e 2017

\footnotetext{
${ }^{14}$ Pelo método 1 , os quatro setores somaram entre 95,6\% e 126,1\% do PIB nos anos mencionados, apresentando a uma variação mais expressiva. Logo, o método 2 mais eficiente.
} 
- de 27,3\% para $12,2 \%$-, no mesmo período o setor de serviços ganhou 18,0 p.p. do PIB - passando de 55,3\% para 73,3\% de participação no PIB. Por sua vez, o auge da participação do setor agropecuário ocorreu no início da década de 1950, quando foi responsável por 13,7\% do PIB em 1952 na série ajustada e compatibilizada com o SCN Ref. 2010 (Gráfico 5).

A partir do Gráfico 5 nota-se três mudanças estruturais principais ocorridas na economia brasileira nas últimas sete décadas. A primeira abrange a redução da parcela agropecuária durante a segunda metade dos anos 1950 até fim da década de 1960, desde quando a parcela deste setor permanece constante entre $5 \%$ e $6 \%$ do PIB. A segunda compreende o período de avanço da industrialização brasileira, da década de 1950 até 1986 . E a terceira envolve a dominância estrutural do setor de serviços diante do retrocesso da industrialização.

\subsection{Análise de sensibilidade da nova série de (des)industrialização corrigida}

A nova série ajustada e compatibilizada para o SCN Ref. 2010 pelo método 2 parece estar mais aderente a realidade brasileira, sobretudo nos períodos em que o dummy financeiro foi elevado, comparativamente a série ajustada pelo método 1 (série usualmente utilizada pelos autores de desindustrialização).

Até 1980 as séries ajustadas pelo método 1 (Gráfico 3) e método 2 (Gráfico 6) têm formatos semelhantes, pois o dummy financeiro não foi representativo. No entanto, a nova série pelo método 2 possui um nível inicial e pico maior. Além da série ajustada pelo método 2 estar compatibilizada para que a participação de todos os setores no PIB seja 100\% e para contornar apenas uma quebra metodológica ao invés de duas, ela também possui a vantagem de maior aderência aos ciclos econômicos pós-1980. ${ }^{15}$ Primeiro, durante a recessão do início dos anos oitenta a participação relativa da manufatura pela nova série diminuiu de $26,2 \%$ para $24,3 \%$, entre 1980 e 1983 (Gráfico 6). ${ }^{16}$ Durante recessões é esperado que a manufatura diminua seu peso no PIB porque ela produz bens elásticos à renda. ${ }^{17}$ Segundo, durante a retomada no período de 1984-1986, a manufatura registrou o nível mais elevado de toda a série de 1947-2017, de 27,3\% do PIB, em 1986 (Gráfico 6). ${ }^{18}$ Neste ano houve forte crescimento da demanda por produtos industriais devido às medidas do Plano Cruzado, sobretudo o congelamento dos preços, que provocou um superaquecimento do consumo nos primeiros meses do Plano. Com a economia aquecida, a taxa de desemprego diminuiu e contribuiu para que o pico da parcela do emprego manufatureiro no emprego total também ocorresse em 1986 (MORCEIRO, 2018). ${ }^{19}$ Terceiro, durante 1990-1992 a manufatura reduziu sua parcela no PIB

\footnotetext{
${ }^{15}$ A nova série exibida no Gráfico 6 está bem aderente ao comportamento do PIB real das Contas Nacionais, da utilização da capacidade instalada (UCI) calculada pela Fundação Getúlio Vargas e da formação bruta de capital fixo (FBCF) de máquinas e equipamentos das Contas Nacionais. Em média, nos períodos de 1981-1983, 1984-1986 e 1990-1992, o PIB real da indústria de transformação variou, respectivamente, $-5,5,+8,6 \%$ e $-5,3 \%$, enquanto o PIB real da economia total variou, respectivamente, $-2,1 \%,+6,9$ e $-1,5 \%$, conforme dados das Contas Nacionais do IBGE. A UCI na indústria reduziu-se 11,3 p.p. na primeira recessão (1981-1983), aumentou 9,5 p.p na retomada (1984-1986) e voltou a reduzir-se 8,8 p.p na segunda recessão (1990-1992). A FBCF de máquinas e equipamentos a preços constantes de 1980 variou, para os mesmos períodos, respectivamente, $-48,0 \%,+58,1 \%$ e $-34,3 \%$.

${ }^{16} \mathrm{Na}$ série tradicionalmente ajustada pelo método 1, a participação da manufatura entre 1980 e 1983 mantém-se estável em torno de $21 \%$ e eleva-se para 21,9\% em 1982 (Gráfico 4).

17 “(...) a indústria brasileira é um setor que produz bens elásticos em relação à renda. Assim, nas fases de prosperidade a indústria tende a aumentar de peso na economia. O oposto ocorre nas fases de estagnação e/ou recessão.” (BONELLI; PESSÔA, 2010, p. 4).

${ }^{18} \mathrm{Na}$ série tradicionalmente ajustada pelo método 1, a parcela da manufatura aumentou em 1984 e 1985 . Neste último ano atingiu o pico 22,8\% do PIB, mas diminuiu para 22,1\% em 1986 (Gráfico 4). No entanto, vale ressaltar que, em valores reais, em 1986, a indústria de transformação cresceu $11,3 \%$ e a economia total $7,5 \%$, conforme dados do SCN Consolidadas.

${ }^{19}$ Em 1986, foram gerados aproximadamente 1,1 milhão de novos empregos na indústria de transformação e a parcela do emprego desta indústria no emprego total da economia brasileira aumentou de 14,7\%, em 1985, para o pico de 16,2\%,
} 
(Gráfico 6), conforme o esperado em período de recessões. ${ }^{20}$ Vale mencionar que na recessão de 1981-1983 e de 1990-1992, houve uma retração do VAB manufatureiro de 15,8\% e 15,3\%, respectivamente; essas quedas foram bem mais intensas que da economia total, de $6,3 \%$ na primeira recessão e 4,5\% na segunda, conforme dados das Contas Nacionais calculados pelo autor.

\section{Gráfico 6 - Indústria de transformação (\% do PIB), Brasil, 1947-2017, a preços correntes: nova série compatibilizada para o SCN Ref. 2010 com o ajuste para o dummy financeiro}

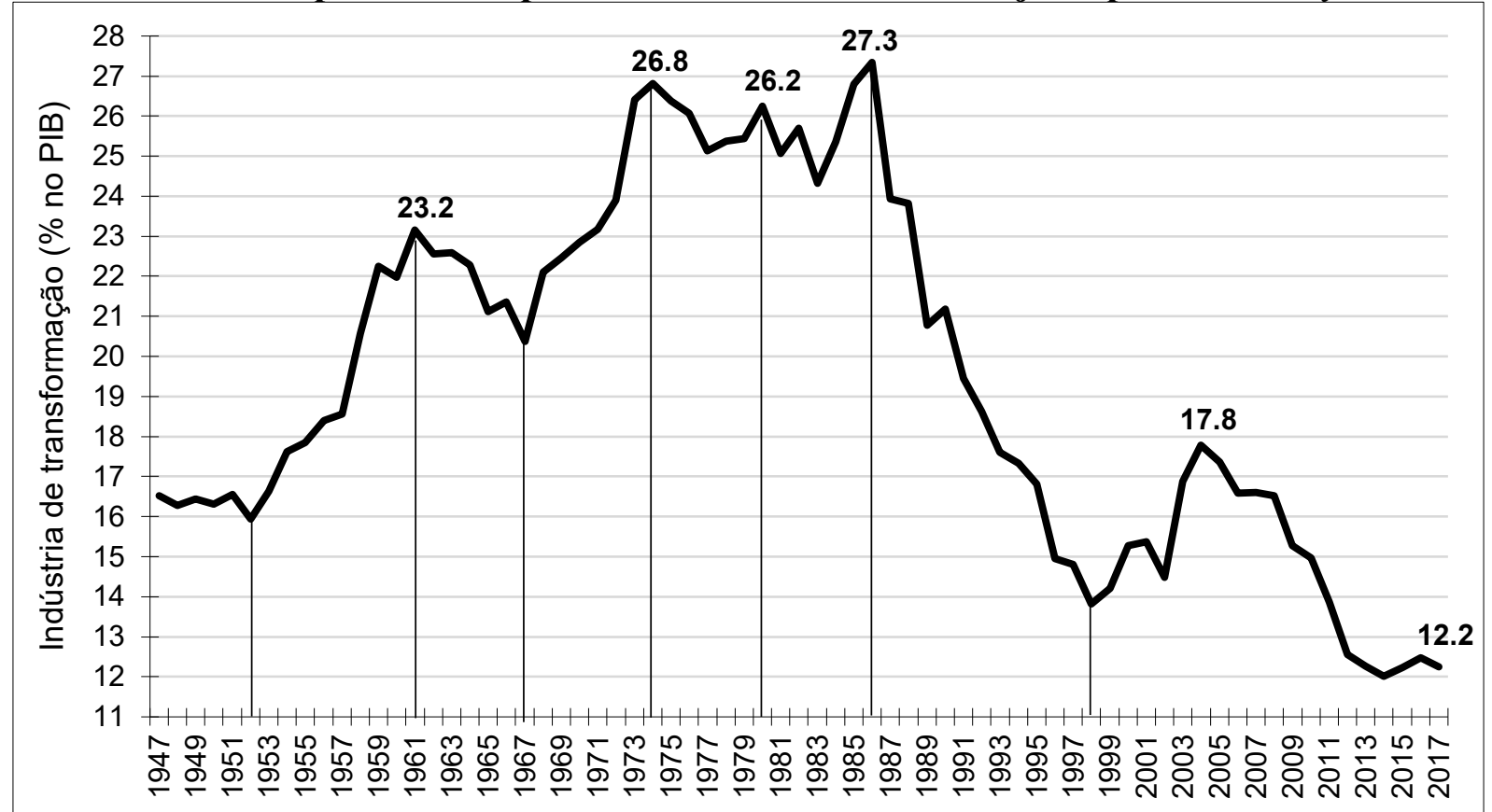

Nota: PIB a custo de fatores de 1947 a 1994 e a preços básicos de 1995 a 2017. SCN Consolidadas para o período 1947-1994 e SCN Ref. 2010 para o período 1995-2017.

Fonte: IBGE (1996, 2006, 2018a). Cálculos e elaboração do autor.

O momento mais agudo da desindustrialização brasileira foi de 1987 a 1998, período em que a manufatura perdeu 15,5 p.p. do PIB (Gráfico 6). O mesmo fato se repete para a série da desindustrialização pelo emprego exibida por Morceiro (2018). Esse foi um período conturbado e com elevadas incertezas que dificultaram o planejamento da produção industrial e postergaram ampliações da capacidade produtiva. Primeiro, a partir de 1987 até 1994 a inflação mudou de patamar e tornou-se elevadíssima. Segundo, houve uma abertura comercial rápida e profunda a partir de 1988 (BIELSCHOWSKY, 1999) em que as tarifas alfandegárias começaram a ser reduzidas e tiveram forte queda até 1992, e as principais barreiras não tarifárias foram removidas em 1990 (KUME; PIANI; SOUZA, 2003). Terceiro, o país passou por vários planos fracassados de estabilização monetária; em um deles o presidente eleito Fernando Collor confiscou a poupança dos cidadãos e passou pelo primeiro processo de impeachment do Brasil e da América Latina. Quarto, o Plano Real, ao mesmo tempo em que reduziu substancialmente a taxa de inflação brasileira, conviveu com taxas de juros reais elevadas e sobrevalorização cambial, desestimulando a produção industrial nacional e favorecendo as importações. Em síntese, o período de 1987 a 1998 desfavoreceu a indústria de transformação brasileira, que perdeu participação tanto pelo PIB (Gráfico 6) quanto pelo emprego Morceiro (2018).

em 1986, conforme dados da Pesquisa Nacional por Amostra de Domicílios (PNAD) do IBGE tabulados por Morceiro (2018).

${ }^{20} \mathrm{Na}$ série tradicionalmente ajustada pelo método 1, a manufatura aumentou seu peso no PIB em 1992. Ademais, como mencionado na seção 3.2, nos anos de 1992 e 1993 houve grande aumento no dummy financeiro no SCN Ref. 1985, o qual foi utilizado para ajustar a série, pelo método 1, de participação da manufatura no PIB. Ao utilizar dados do SCN Ref. 1985, acredita-se que o ajuste está muito contaminado pelo comportamento do dummy financeiro. 


\section{Conclusão}

Este estudo apresenta dados inéditos e evidências empíricas novas para o debate de desindustrialização brasileiro, os quais permitem fazer uma avaliação mais precisa do processo de desindustrialização pela participação no PIB.

A principal contribuição deste estudo foi apresentar evidências empíricas de que a série de participação da indústria de transformação no PIB brasileiro está sobrestimada, sobretudo no período anterior e durante a liberalização comercial, devido à forma incorreta como a série foi usualmente mensurada em vários estudos de desindustrialização. Dessa forma, tais evidências colocam em dúvida a tese da sobre-industrialização de Bonelli e Pessôa (2010) e Bonelli, Pessôa e Matos (2013), uma vez que essa sobre-industrialização pode ter decorrido da sobrestimação do peso da indústria de transformação no PIB.

Este estudo identificou que os usuários das Contas Nacionais mensuraram de forma errada a participação setorial no PIB (a preços básicos ou a custo de fatores), provavelmente devido ao desconhecimento do dummy financeiro presente nas Contas Nacionais do século XX. Para corrigir o problema causado pelo dummy financeiro e eliminar as duas descontinuidades metodológicas da série de (des)industrialização considerada oficial pela literatura, este estudo desenvolveu um método próprio. A partir desse método, apresentamos uma nova série da participação da indústria de transformação no PIB que é mais aderente aos ciclos econômicos pelos quais vivenciou a economia brasileira comparativamente a série que corrige apenas as descontinuidades metodológicas. A nova série está ajustada e compatibilizada para a metodologia atual das Contas Nacionais que o IBGE adota e pode ser replicada para os demais setores que compõem a economia e comparar os resultados de longo prazo entre os setores. Ressalta-se que a série de (des)industrialização usualmente utilizada pela literatura está desbalanceada, isto é, a soma das parcelas dos setores que compõem a economia ultrapassa $100 \%$ do PIB.

Além disso, este trabalho exibiu séries da participação da indústria de transformação no PIB com a mesma metodologia para períodos mais extensos que as séries exibidas pela literatura. As séries utilizadas pela literatura apresentam descontinuidades metodológicas entre 1989 e 1990 e entre 1994 e 1995. Por não apresentarem descontinuidades metodológicas, as séries exibidas na seção 3.1 permitem analisar se houve desindustrialização no período anterior e posterior a abertura comercial, suprindo a ausência de informações apontada por Torres e Cavalieri (2015).

Estudos futuros poderiam investigar detalhadamente as mudanças metodológicas que causaram descontinuidades na série de participação setorial do PIB, pois essas mudanças reduziram o peso da indústria brasileira no PIB. Além disso, a série de longo prazo do índice de preços relativos entre a indústria de transformação e a economia total deve levar em conta o problema do dummy financeiro apontado neste estudo.

\section{Referências}

BIELSCHOWSKY, R. Investimentos na indústria brasileira depois da abertura e do Real: o mini-ciclo de modernizações, 1995-1997. Série Reformas Económicas No. 44. Brasília: CEPAL, 1999.

BONELLI, R.; PESSÔA, S. de A. Desindustrialização no Brasil: um resumo da evidência: Texto para Discussão No. 7. Rio de Janeiro: IBRE/FGV-RJ, 2010.

BONELLI, R.; PESSÔA, S.; MATOS, S. Desindustrialização no Brasil: fatos e interpretação. In: BACHA, E.; BOLLE, M. B. DE (Ed.). O futuro da indústria no Brasil: desindustrialização em debate. 1. ed. Rio de Janeiro: Civilização Brasileira, 2013. p. 45-79. 
BRESSER-PEREIRA, L. C.; MARCONI, N. Existe doença holandesa no Brasil? In: BRESSERPEREIRA, L. C. (Ed.). Doença holandesa e indústria (coletânea). Rio de Janeiro: Editora FGV, 2010.

CANO, W. A desindustrialização no Brasil. Economia e Sociedade, v. 21, n. Número Especial, p. 831-851, 2012.

FEIJÓ, C. A. Desindustrialização e os dilemas do crescimento econômico recente. São Paulo: Instituto de Estudos para o Desenvolvimento Industrial (IEDI), 2007.

FEIJÓ, C. A.; CARVALHO, P. G. M. de; ALMEIDA, J. S. G. de. Ocorreu uma desindustrialização no Brasil? São Paulo: Instituto de Estudos para o Desenvolvimento Industrial (IEDI), 2005. .

FIESP - FEDERAÇÃO DAS INDÚSTRIAS DO ESTADO DE SÃO PAULO. Por que reindustrializar o Brasil? São Paulo: FIESP, 2013.

FIESP; CIESP. O desafio de posicionar o Brasil na rota do desenvolvimento. São Paulo: Federação das Indústrias do Estado de São Paulo (FIESP); Centro das Indústrias do Estado de São Paulo (CIESP), 2018.

HALLAK NETO, J.; FORTE, C. M. O sistema de contas nacionais: evolução histórica e implantação no Brasil. Revista Econômica, v. 18, n. 1, 2016.

HIRATUKA, C.; SARTI, F. Transformações na estrutura produtiva global, desindustrialização e desenvolvimento industrial no Brasil. Revista de Economia Política, v. 37, n. 1, p. 189-207, 2017.

IBGE - INSTITUTO BRASILEIRO DE GEOGRAFIA E ESTATÍSTICA. Sistema de contas nacionais consolidadas: Brasil (Série relatórios metodológicos, n. 8). Rio de Janeiro: IBGE, 1990a.

IBGE. Estatísticas históricas do Brasil: séries econômicas, demográficas e sociais de 1550 a 1988.

2. ed. Rio de Janeiro: IBGE, 1990b. v. 3

IBGE. Contas consolidadas para a nação - Brasil: 1980-1993. Rio de Janeiro: IBGE, 1994.

IBGE. Contas consolidadas para a nação - Brasil: 1990-1995. Rio de Janeiro: IBGE, 1996.

IBGE. Sistema de contas nacionais: Brasil: 2003. Rio de Janeiro: IBGE, 2004a.

IBGE. Sistema de contas nacionais: Brasil. 1. ed. Rio de Janeiro: IBGE. (Série relatórios metodológicos, n. 24), 2004b.

IBGE. Estatísticas do século XX. Rio de Janeiro: IBGE, 2006.

IBGE. Sistema de contas nacionais: Brasil. 2. ed. Rio de Janeiro: IBGE. (Série relatórios metodológicos, n. 24), 2008.

IBGE. Sistema de contas nacionais: Brasil: 2005-2009. Rio de Janeiro: IBGE, 2011.

IBGE. Retroprojeção da população do Brasil por sexo e idade: 2000-1980. Rio de Janeiro: IBGE, 2016.

IBGE. Contas Nacionais Trimestrais: $3^{\circ}$ trimestre de 2018. Rio de Janeiro: IBGE, $2018 \mathrm{a}$.

IBGE. Sistema de contas nacionais: Brasil 2016. Rio de Janeiro: IBGE, 2018b.

MARCONI, N.; ROCHA, M. Taxa de câmbio, comércio exterior e desindustrialização precoce - o caso brasileiro. Economia e Sociedade, v. 21, n. Número Especial, p. 853-888, 2012. 
MORCEIRO, P. C. Desindustrialização na economia brasileira no período 2000-2011: abordagens e indicadores. São Paulo: Cultura Acadêmica, 2012.

MORCEIRO, P. C. A indústria brasileira no limiar do século XXI: uma análise da sua evolução estrutural, comercial e tecnológica. 198 f. Tese (Doutorado em Economia) - Faculdade de Economia, Administração e Contabilidade, Universidade de São Paulo, São Paulo, 2018.

MOREIRA, M. M. A indústria brasileira nos anos 90: o que já se pode dizer? In: GIAMBIAGI, F.; MOREIRA, M. M. (Ed.). A Economia Brasileira nos Anos 90. Rio de Janeiro: BNDES, 1999. 1p. 293-332.

NASSIF, A. Há evidências de desindustrialização no Brasil ? v. 28, n. 109, p. 72-96, 2008.

NASSIF, A.; BRESSER-PEREIRA, L. C.; FEIJÓ, C. The case for reindustrialisation in developing countries: towards the connection between the macroeconomic regime and the industrial policy in Brazil. Cambridge Journal of Economics, v. 42, n. 2, p. 355-381, 2017.

OREIRO, J. L.; FEIJÓ, C. A. Desindustrialização: conceituação, causas, efeitos e o caso brasileiro. Revista de Economia Política, v. 30, n. 2, p. 219-232, 2010.

PALMA, J. G. Four sources of "de-industrialization" and a new concept of the "dutch disease". In: OCAMPO, J. A. (Ed.). Beyond reforms: structural dynamics and macroeconomic vulnerability. Washington, DC: Stanford University Press : The World Bank, 2005. p. 71-116.

RODRIK, D. Premature deindustrialization. Journal of Economic Growth, v. 21, n. 1, p. 1-33, 2016.

SINGH, A. Manufacturing and de-industrialization. In: EATWELL, J.; MILGATE, M.; NEWMAN, P. (Ed.). The New Palgrave: A Dictionary of Economics. London: Macmillan, 1987. p. Vol. 3, 301308.

SNA 2008. System of national accounts 2008. New York: European Comission; International Monetary Fund; Organisation for Economic Co-operation and Development; United Nations; Bank World, 2009.

TORRES, R. L.; CAVALIERI, H. Uma crítica aos indicadores usuais de desindustrialização no Brasil. Revista de Economia Política, v. 35, n. 141, p. 1-20, 2015.

TREGENNA, F. Characterising deindustrialisation: an analysis of changes in manufacturing employment and output internationally. Cambridge Journal of Economics, v. 33, n. 3, p. 433-466, 2009.

TREGENNA, F. Deindustrialisation: an issue for both developed and developing countries. In: WEISS, J.; TRIBE, M. (Ed.). Routledge Handbook of Industry and Development. London: Routledge, 2016a. p. 97-115.

TREGENNA, F. Deindustrialization and premature deindustrialization. In: REINERT, E.; GHOSH, J.; KATTEL, R. (Ed.). Handbook of Alternative Theories of Economic Development. Cheltenham, UK; Northampton, MA, USA: Edward Elgar Publishing, 2016b. p. 710-728. 